\title{
Prevalence and associations for use of a traditional medicine provider in the SAMINOR 1 Survey: a population-based study on Health and Living Conditions in Regions with Sami and Norwegian Populations
}

Agnete Egilsdatter Kristoffersen ${ }^{1 *}$, Trine Stub ${ }^{1}$, Marita Melhus ${ }^{2}$ and Ann Ragnhild Broderstad ${ }^{2,3}$

\begin{abstract}
Background: In Northern Norway, traditional medicine (TM) is shaped by both Christianity and traditional Sami nature worship. The healing rituals may include prayer and the use of tools such as moss, water, stones, wool and soil. Examples of TM modalities offered is cupping, blood-stemming, laying on of hands, healing prayers, and rituals. The purpose of this study was to investigate the prevalence of the use of TM in areas with predominantly Sami and Norwegian populations, and the influence of ethnicity, geography, gender, age, education, household income, religiosity and self-reported health on such use.

Methods: The study is based on data collected in the first SAMINOR Survey (SAMINOR 1) conducted in 2003/2004, including three self-administered questionnaires, clinical measures, and blood analyses. Data was collected in 24 municipalities in Norway known to have a substantial population of Sami. All residents aged 30 and 36-78/79 years in the predefined regions were invited regardless of ethnic background ( $N=27,987)$. Of these, 16,865 (60.3\%) accepted to participate and gave their consent to medical research.

Results: Of the 16,544 people responding to the question about TM use, 2276 (13.8\%) reported to have used TM once or more during their lifetime. The most outstanding characteristic of the TM users was the affiliation to the Laestadian church, where 34.3\% $(n=273)$ reported such use, followed by an inner Finnmark residence $(31.1 \%, n=481)$ and a Sami ethnicity $(25.7 \%, n=1014)$. Women were slightly more likely to use TM compared to men ( $15.9 \%$ and $11.5 \%$ accordingly, $p<0.001$ ), and the TM users were slightly younger than the non-TM users (mean age 52.3 versus 54 . 3 years, $p<0.001)$. The TM users also had lower income $(p<0.001)$ than the non-TM users. We found no significant differences between the TM users and the non-TM users concerning years of education, and whether the participants were living with a spouse/partner or not.
\end{abstract}

Conclusion: Further studies are necessary to examine the development of TM use in Norway over time, and use in areas with mainly Norwegian inhabitants. There is also a lack of studies quantifying TM use among Sami people in Sweden, Finland and Russia.

Keywords: Traditional medicine, Traditional healing, Spiritual healing, Sami, Norway, Religious healing

\footnotetext{
* Correspondence: agnete.kristoffersen@uit.no

${ }^{1}$ National Research Center in Complementary and Alternative Medicine

(NAFKAM), Department of Community Medicine, Faculty of Health Science,

UiT The Arctic University of Norway, Tromsø, Norway

Full list of author information is available at the end of the article
} 


\section{Background}

There have always been people of different ethnic backgrounds in Northern Norway. They speak different languages and belong to different cultures, such as Sami, Kven (Finnish descent) and Norwegians [1]. The Sami is a group of people with Finno-Ugric origin, settled in the northern part of Norway, Sweden, Finland and Russia and the only indigenous people in Scandinavia. Traditionally the Sami lived as farmers and fishermen or with a seminomadic life as reindeer herders [2, 3]. The largest Sami population is found in Norway where they have their own language, cultural history, rights $[3,4]$ and a Sami parliament [5]. No reliable or updated demographic record of the Sami exists. The accurate number of Sami people living in Norway today is not clear as ethnicity is not registered in public registers [6]. Many inhabitants of Northern Norway have in addition a mixture of Sami, Kven and Norwegian ancestors. Estimates, however, vary between 40,000 and 80,000 in accordance with the criteria used (heritage, mother tongue and sense of belonging to the Sami etc.). It is a great deal of diversity regarding Sami affiliation across the geographical regions within the Sami population. The traditional Sami settlements are demonstrated in Fig. 1, although the Sami people today live all over Norway.

Complementary and Alternative Medicine (CAM) is defined as a treatment modality that is used alongside conventional treatments, but not considered standard medical treatments [7]. The most commonly used CAM modalities in Norway are massage, acupuncture, naprapathy, reflexology, osteopathy, cupping and healing [8]. Among the CAM modalities offered in Norway is traditional healing, also categorized as traditional medicine (TM). TM draws on a long history and is understood as "the sum total of the knowledge, skills, and practices based on the theories, beliefs, and experiences indigenous to different cultures [...], used in the maintenance of health as well as in the prevention, diagnosis, improvement or treatment of physical and mental illness" [9]. The term traditional medicine is in some countries used interchangeably with complementary and alternative medicine [10]. In Norway, however, TM is considered a treatment modality under the CAM umbrella.

The TM used in Northern Norway is shaped by both Christianity and traditional Sami nature worship [11]. The healing rituals may include prayer and the use of tools such as moss, water, stones, wool and soil [12]. Examples of TM modalities offered in Northern Norway is cupping, blood-stemming, laying on of hands, healing prayers (called reading), and rituals [13]. The healing gifts are passed from healers to selected people who show signs of healing abilities or a calling for such work - often a younger member within the healer's close family [14].
The traditional healers are mostly non-professional and non-commercial therapists $[13,15]$. Treatment is often available within the family and mostly free of charge. In 1975 Efskind and Johansen found that 34\% (n $=41$ ) of the participants in a survey conducted in a small town in Northern Norway reported to have used TM sometime in the past [16]. In 2005, Sørlie et al. found that $50 \%(n=34)$ of the patients following psychiatric hospital treatment reported previous visits to TM providers. They found this more often among Sami patients $(64.5 \%, n=20)$ than among Norwegian patients $(37.8 \%, n=14)$ [17]. In 2006 Bakken et al. found that modern or traditional healing was used by $16 \%(n=$ 2675) of the participants in the first population-based study on Health and Living Conditions in Regions with Sami and Norwegian Populations (the SAMINOR 1 Survey). She also found that participants with a Sami background were more frequent users of healing than the non-Sami participants [18].

Knowledge about the use of TM is important to secure a patient centered health care. While several qualitative studies gathered important knowledge about how TM is practiced, studies quantifying the use in different groups are still limited.

Thus, the purpose of this study was to investigate the prevalence of the use of TM in areas with predominantly Sami and Norwegian populations, and the influence of ethnicity, geography, gender, age, education, household income, religiosity and self-reported health on such use.

\section{Methods \\ Participants \\ The SAMINOR Survey}

The SAMINOR Survey was designed to provide more information about health and living conditions in areas with mixed Sami and Norwegian settlements in Norway. The first survey (SAMINOR 1) was carried out between January 2003 and April 2004 and included 16,865 participants. The second survey (SAMINOR 2) was conducted in two steps. The SAMINOR 2 Questionnaire Survey was carried out between January 2012 and October 2012 and included 11,600 participants. The SAMINOR 2 Clinical Survey was carried out between September 2012 and June 2014 and included 6004 participants.

This study was based on data collected in the SAMINOR 1 Survey [2] as the SAMINOR 2 Survey did not include questions regarding use of TM. SAMINOR 1 was conducted by the Centre for Sami Health Research in collaboration with the Norwegian Institute of Public Health. The chosen areas were based on areas where more than $5-10 \%$ of the population reported themselves to be Sami [2] in the 1970 census, as described in the report The Lappish population in Northern Norway [19]. 


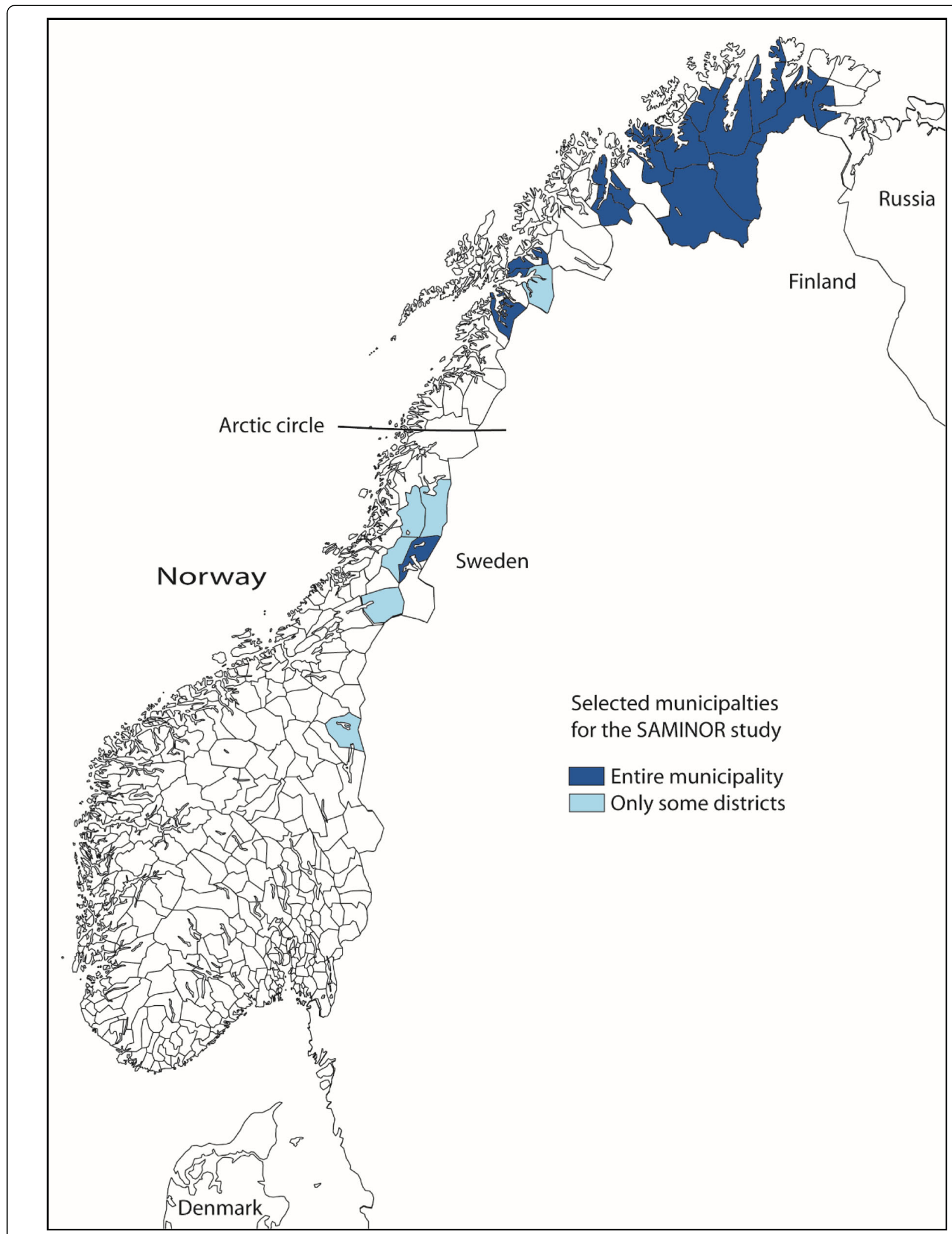

Fig. 1 Map of the Sami settlements in Norway and the municipalities included in the four geographical regions. Republished with permission from Center for Sami Health Research 
In addition, historical and local knowledge were taken into account.

The SAMINOR 1 Survey included three self-administered questionnaires, clinical measures, and blood analyses. Data was collected in 24 municipalities (Fig. 1), known to have a substantial population of Sami, though only selected districts were included in some of the municipalities. Except for the municipality of Alta, all included municipalities were small $(<3000$ inhabitants) and rural. All residents aged 30 and 36-78/79 years were invited, regardless of ethnic background $(n=27,987)$. Of these, $16,865(60.3 \%)$ accepted to participate and gave their consent to medical research. This study was based on data retrieved from the questionnaires. The initial questionnaire (Q1), including the questions about TM use, ethnicity and income was completed by 16,544 (response rate 59.1\%). Of these 15,730 completed the second questionnaire (Q2) including the health related questions while the third questionnaire (Q3) including church affiliation was completed by 13,547 . The response rate was higher for women and in the older (36-78/9) age group. In the first four municipalities, the first questionnaire (Q1) followed the invitation to participate in the study. A second questionnaire (Q2) was sent out alongside the letter confirming the time and place for the clinical examination. In the remaining municipalities, the first and second questionnaires were combined and sent together with an invitation to participate in a clinical examination. After the clinical examination, the participants were asked to answer a third questionnaire (Q3) and return this by post.

\section{Ethnicity}

Ethnicity was determined by eleven questions regarding home language, ethnic background and self-perceived ethnicity/identity: What language(s) do/did you, your parents and your grandparents use at home? The questions were to be answered separately for each relative. The response categories were "Norwegian", "Sami", "Kven" (Finnish immigrants), or "Other". Providing the same response options, we asked: What is your, your father's and your mother's ethnic background? The respondents also reported whether they considered themselves to be Norwegian, Sami, Kven or other. On all these questions, multiple answers were allowed. Based on these questions, participants were categorized into three groups: Sami, Sami affiliation or Non-Sami.

Sami was defined by customization (counts himself as Sami or reported having Sami ethnic background) and language criterion (Sami language in at least one of their grandparents, parents or themselves).

Sami affiliation was defined by crossing Sami for at least one question, without meeting the full criteria above.

Non-Sami: Those who were not included in the two above mentioned categories including Norwegians, Kvens and others.

\section{Geographical regions}

In line with Naseribafrouei et al. [20], we defined four geographical regions (Fig. 2):

Region 1: The inland of Finnmark county, including Karasjok and Kautokeino.

Region 2: The inland and coastal areas of Finnmark county, including Porsanger, Tana and Nesseby.

Region 3: The coastal areas of Finnmark and the northern part of Troms county, including Lyngen, Storfjord, Kåfjord, Kvænangen, Alta, Loppa, Kvalsund and Lebesby.

Region 4: Marka, Lule and South Sami areas in Southern Troms, Nordland, Nord- and Sør-Trøndelag counties, including Lavangen, Evenes, Skånland, Tysfjord, and Røyrvik. In addition, some selected school districts were included: Vassdalen in Narvik municipality, Hattfjelldal in Hattfjelldal municipality, Trones and Furuly in Namsskogan, Majavatn in Grane, Vinje in Snåsa, and Brekken in Røros.

\section{Measures \\ Use of traditional medicine}

In this study, a user of TM was measured by visits to a TM provider (traditional healer). The TM provider asked for in the questionnaire (guvllar, reader, blower, hands on healer) are known to base their practice on religion and religious rituals, such as prayers and the laying on of hands. Many have special abilities such as warm hands and clairvoyance [21]. In addition, many use herbs and rituals as a part of their service [12].

In the questionnaire the participants were asked "If you have ever used alternative providers, which have you used?" The responses were traditional healer (guvllar, reader, blower, hands on healer); modern healer; acupuncturist; reflexologist, homeopath, kinesiologist (etc). All participants who checked for traditional healer (guvllar, reader, blower, hands on healer) were considered users of TM. There was not provided any definition of a traditional healer apart from the examples given in the parenthesis (guvllar, reader, blower, hands on healer).

\section{Self-reported health and health complaints}

The general health condition was measured as a response to the question: How is your current health? where we merged the original four responses: Poor, not good, good and excellent into poor and good health.

The report of spesific health complaints were mainly reported as a yes-response to the question: Do you have or have you had.... followed by the listed complaints. Exceptions were daily cough, which was a yes-response to the question Do you cough more or less daily for some 


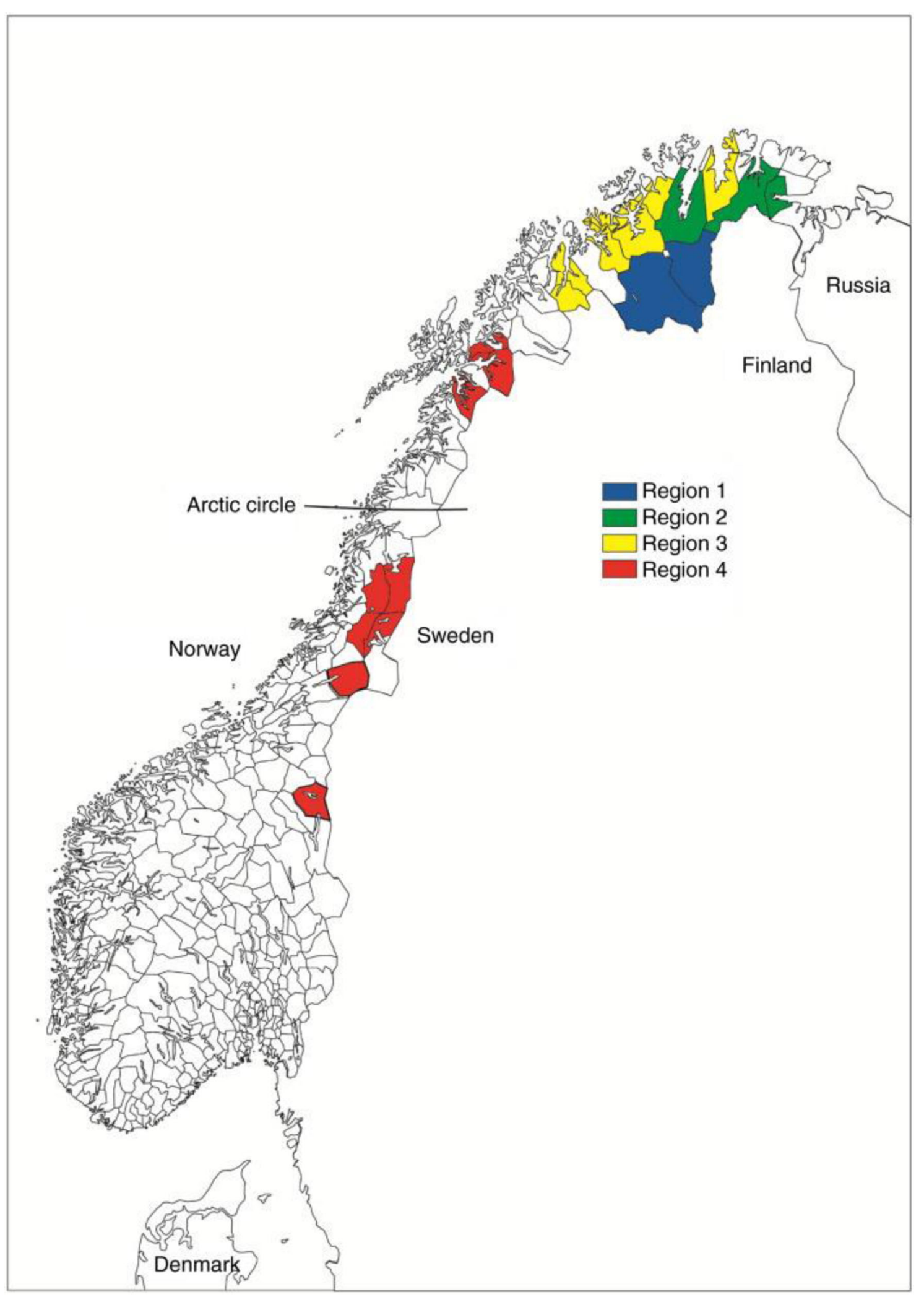

Fig. 2 Selected municipalities for the SAMINOR 1 survey. Republished with permission from Center for Sami Health Research 
periods of the year?; insomnia, which was a yes-response to Do you from time to time suffer from sleeplessness/insomnia? and sad/depressed, which was a yes-response to Does it happen that you for longer periods (>14 days) feel sad and depressed?

The questions During the last 14 days, have you felt unable to cope with your difficulties?and Do you sometimes feel lonely? have alle avilable response categories presented in Table 2. Fracture was a yesresponse to either fracture in wrist/underarm or fracture in the femoral/neck.

\section{Socio-demographic variables}

We defined three education response categories from the original continuous variable referring to the number of years of education: Primary education (0-9 years), secondary education (10-12 years) and college/university education (13 years or more). The income variable referred to the household's total gross income in the previous year. Six original response categories were merged into low income $(<\mathrm{NOK} 300,000(€ 32,000))$, middle income (NOK 300,000-600,000 (€ 32,000$63,000)$ ) and high income (> NOK 600,000 (€ 63,000).

Table 1 Basic characteristics of the total sample and among users and non-users of TM

\begin{tabular}{|c|c|c|c|c|c|c|c|}
\hline & \multicolumn{2}{|c|}{ Total sample } & \multicolumn{2}{|c|}{ TM users } & \multicolumn{2}{|c|}{ No TM users } & \multirow[t]{2}{*}{$p$-value ${ }^{*}$} \\
\hline & $\%$ & $\mathrm{n}^{* *}$ & $\%$ & $\mathrm{n}$ & $\%$ & $\mathrm{n}$ & \\
\hline \multicolumn{8}{|l|}{ Age } \\
\hline Mean & 54.05 & 16,544 & 52.3 & 2276 & 54.3 & 14,268 & $<0.001$ \\
\hline Range & $(30-79)$ & 16,544 & $30-78$ & 2276 & $30-79$ & 14,268 & \\
\hline Gender & & & & & & & $<0.001$ \\
\hline Men & 48.2 & 7973 & 11.5 & 914 & 88.5 & 7196 & \\
\hline Women & 51.8 & 8571 & 15.9 & 1362 & 84.1 & 7393 & \\
\hline Living with a spouse/partner & & & & & & & 0.089 \\
\hline Yes & 76.6 & 10,176 & 13.4 & 1366 & 86.6 & 8810 & \\
\hline No & 23.4 & 3105 & 14.6 & 454 & 85.4 & 2651 & \\
\hline Household income & & & & & & & $<0.001$ \\
\hline Low (< NOK 300'/ € 32') & 38.9 & 5808 & 15.6 & 907 & 84.4 & 4901 & \\
\hline Middle (NOK 300'-600'/€ 32'-63') & 49.8 & 7433 & 13.6 & 1008 & 86.4 & 6425 & \\
\hline High (>NOK 600'/€ 63') & 11.3 & 1685 & 11.8 & 199 & 88.2 & 1486 & \\
\hline Years of Education & & & & & & & 0.250 \\
\hline Primary (0-9 years) & 37.0 & 5465 & 14.3 & 784 & 85.7 & 4681 & \\
\hline Secondary (10-12 years) & 30.1 & 4437 & 13.2 & 585 & 86.8 & 3852 & \\
\hline College/university (13 years or more) & 32.9 & 4862 & 13.8 & 673 & 86.2 & 4189 & \\
\hline Ethnicity & & & & & & & $<0.001$ \\
\hline Sami & 23.9 & 3946 & 25.7 & 1014 & 74.3 & 2932 & \\
\hline Sami affiliation & 11.4 & 1885 & 15.6 & 294 & 84.4 & 1591 & \\
\hline Non-Sami & 64.6 & 10,649 & 9.1 & 964 & 90.9 & 9685 & \\
\hline Area of living & & & & & & & $<0.001$ \\
\hline Region 1 & 9.4 & 1548 & 31.1 & 481 & 68.9 & 1067 & \\
\hline Region 2 & 16.4 & 2719 & 11.3 & 306 & 88.7 & 2413 & \\
\hline Region 3 & 53.2 & 8809 & 13.3 & 1170 & 86.7 & 7639 & \\
\hline Region 4 & 21.0 & 3468 & 9.2 & 319 & 90.8 & 3149 & \\
\hline Church affiliation & & & & & & & $<0.001$ \\
\hline Church of Norway & 83.7 & 11,121 & 12.8 & 1423 & 87.2 & 9698 & \\
\hline The Laestadian church & 6.0 & 795 & 34.3 & 273 & 65.7 & 522 & \\
\hline Other church /religion & 2.3 & 312 & 15.7 & 49 & 84.3 & 263 & \\
\hline Not a member of any church /religion & 8.0 & 1060 & 8.5 & 90 & 91.5 & 970 & \\
\hline
\end{tabular}

*Pearson's chi-square test; '1000; ** Due to different number of respondents to the three questionnaires used in the study $(\mathrm{Q} 1=16,544, \mathrm{Q} 2=15,730$ and $\mathrm{Q} 3=$ $13,547)$ and missing responses to some of the questions, the number of respondents in single questions does not always add up to $n=16,544$ 


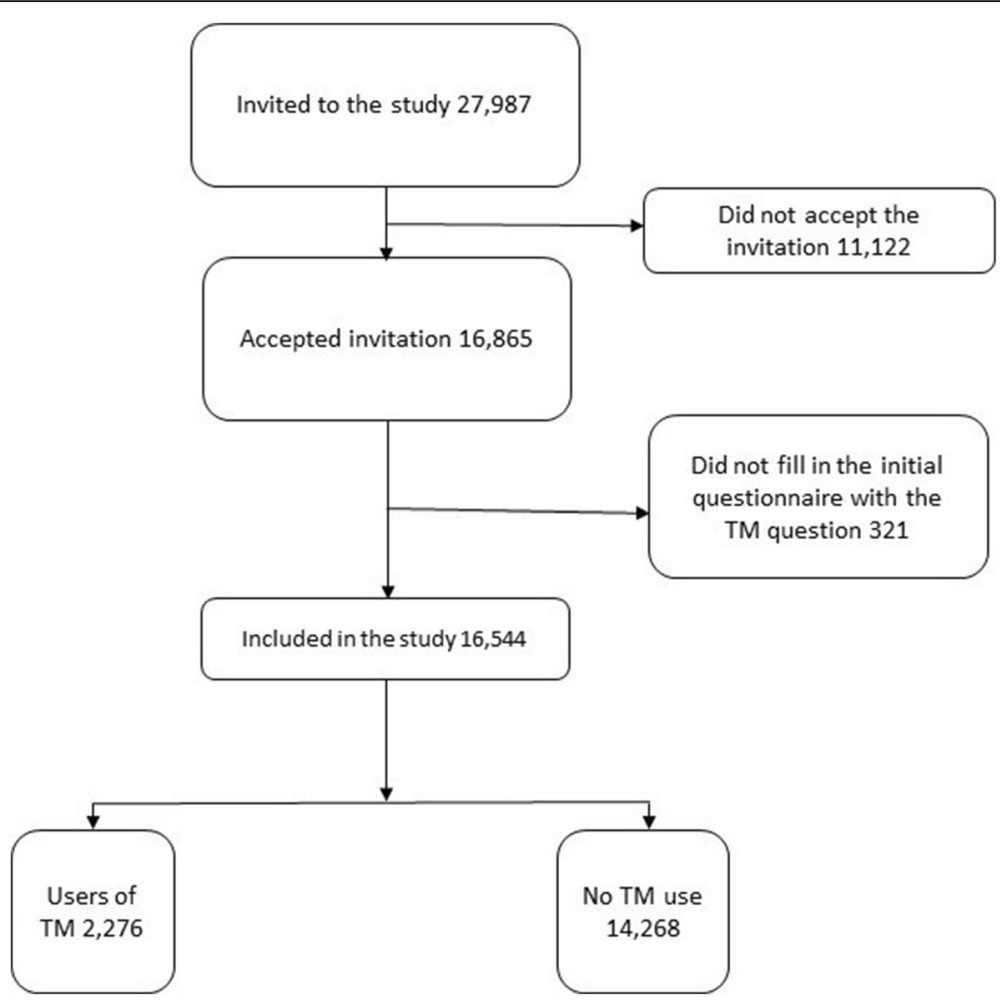

Fig. 3 Flow chart of the included participants

\section{Church affiliation}

The church affiliation was mapped through the following question: Do you have an affiliation to any of the following churches/religious church communities? With the options: Member of The Church of Norway; The Laestadian church; Other church community; Not a member of any church.

The Church of Norway is a Lutheran denomination of Protestant Christianity that serves as the people's church of Norway. It is by far the largest church in Norway, and until the nineteenth century membership was mandatory for everyone [22]. Today the church of Norway has 3,758,070 members constituting $71.5 \%$ of the total population [23]. Laestadianism is a conservative Lutheran revival movement started in Lapland in the middle of the nineteenth century, named after the Swedish state church administrator and temperance movement leader Lars Levi Laestadius. It has members mainly in Finland, North America, Norway, Russia and Sweden [24, 25]. The number of Laestadians worldwide is estimated at between 144,000 and 219,000 [24] of which 50,000 [26] are estimated to live in Norway.

\section{Statistical analysis}

Between-group differences were analyzed using the Pearson's chi-square tests for binary data analyzing one variable at the time and one-way ANOVA test for continuous data in SPSS for Windows (version 24.0, SPSS, Inc., Chicago,
IL). The significance level was defined as $p<0.05$ without $p$-value adjustment for multiple comparisons.

\section{Results}

Basic characteristics of the participants

As shown in Table 1, the mean age of the participants was 54 years with a range of 30-79 years. There were more women $(51.8 \%, n=8571)$ than men $(48.2 \% n=7973)$. Most of the participants had low to middle income $(88.7 \%, n=$ $13,241)$ and lived by the coast $(77.8 \%, n=12,865)$, mainly in region 3 (coastal areas in Finnmark and the northern part of Troms, $53.2 \%, n=8809)$, classified as Non-Sami $(64.6 \%$, $n=10,649)$ and were members of Church of Norway (83.7\%, $n=11,121$ ) (Table 1, left column). The Non-Sami group consisted mainly of Norwegians (93.6\%, $n=9969)$. The rest considered themselves either as Kvens $(1.8 \%, n=$ 196) or "other" $(4.5 \%, n=335)$ (Table 1$)$.

\section{Use of traditional medicine}

From the sample of 16,544 participants included in the analyses, 5419 (32.8\%) reported ever use of CAM. Of these $2276(13.8 \%)$ reported to have visited a traditional healer (guvllar, reader, blower, and hands on healer) (Fig. 3). In comparison, $766(4.6 \%)$ reported to have seen a modern healer, 2467 (14.9\%) had seen an acupuncturist, and 1991 (12\%) had seen other CAM providers (reflexologist/homeopath/kinesiologist, etc). Only 828 participants had used 
both TM and other forms of CAM. Of these, 299 had combined TM with modern healing, 508 had combined TM with acupuncture and 506 had combined TM with reflexology/homeopathy/kinesiology, etc.

\section{Church affiliation}

The most outstanding characteristic of the TM users was affiliation to the Laestadian church, where $34.3 \%$ $(n=273)$ of the affiliates reported to have used TM compared to $8.5-15.7 \%$ of the affiliates of other churches/religions (Table 1).

\section{Area of living}

Also living in region 1 (inner Finnmark) was a strong predictor for TM use, reported to be used by $31.1 \%$ $(n=481)$ of the participants from this area where 9.1\% of the studied population lived. In comparison, $13.3 \%(n=1170)$ of the participants living in region 3 (costal Northern Troms and Finnmark), 11.3\% ( $n=$ 306 ) of the participants living in region 2 (costal Finnmark) and $9.2 \%(n=319)$ of the participants living in region 4 (Nordland and Southern Troms) reported to have used TM (Table 1). Participants with inland residence were more likely to have used TM than participants with coastal residents $(18.2 \%, n=$ 670 and $12.5 \%, n=1606$, respectively).

\section{Ethnicity}

Sami participants were more likely to have used TM $(25.7 \%, n=1014)$ compared to participants with a Sami affiliation $(15.6 \%, n=294)$ and non-Sami participants $(9.1 \%, n=964)$ (Table 1).

When Sami participants were compared to non-Sami participants, we found similar associations for TM use regarding age, gender, self-reported health and income. Differences were, however, found regarding education as more Sami than non-Sami users of TM had university education $(38.4 \%$ vs. $29.7 \% . p<0.001)$ (Table 1$)$.

\section{Gender, age and income}

Women were slightly more likely to use TM compared to men (15.9 and $11.5 \%$, respectively, $p<0.001)$, and the TM users were slightly younger than the non-users of TM (mean age 52.3 versus 54.3 years, $p<0.001$ ). TM users also had lower income $(p<0.001)$ than the non-users of TM. We found no significant differences between TM users and non-TM users in general concerning years of education and whether the participants were living with a spouse/partner or not (Table 1).

\section{Health}

As shown in Table 2, most of the participants reported good health $(68 \%, n=10,565)$ despite the fact that many of the participants also reported health complaints. The most commonly reported complaints were pain and stiffness in muscles or joints reported by $42.7 \%(n=6392)$ of the participants, followed by insomnia $(35.3 \%, n=4612)$ and daily cough $(16 \%, n=$ 2134) (Table 2, left column).

More participants with poor than good health reported to have used TM $(17.5 \%, n=874$ and $11.7 \%, n=1233$, respectively, $p<0.001$ ) (Table 2). Among the TM users, the health problem that was most frequently reported was pain and stiffness in muscles or joints $(n=1006)$, followed by loneliness (sometimes or often) $(n=830)$ and insomnia $(n=733)$ (Table 2$)$ representing 44\%, 36\% and $32 \%$ of the TM users.

Participants with multiple sclerosis reported the highest use of TM $(26.3 \%, n=10)$, followed by participants with ulcerous colitis $(22.3 \%, n=39)$, loneliness (often) $(21.7 \%, n=104)$, and psychological problems $(20.7 \%$, $n=361)$ (Table 2).

\section{Discussion \\ Main findings}

Of the 16,544 people included in the study, 2276 (13.8\%) reported to have used TM at some point in their lives. Only 828 (36.4\%) of these had also used other forms of CAM. The typical user of TM is a Sami woman affiliated to the Laestadian church with rather low income living in the inland of Northern Troms or Finnmark.

\section{Prevalence of TM}

Comparisons of TM use between different studies are challenging, as questions concerning TM use, as well as the setting in which the information is collected, may differ. Previous studies of TM use among Sami and Non-Sami participants in Norway have a rather low number of participants and many include specific patient groups rather than unselected populations. To the best of our knowledge in 2017, this is the first population-based study to investigate the prevalence of TM use among Sami and Non-Sami adults in a large geographical area.

The finding of $13.8 \%$ use of TM is somewhat lower than what was found in smaller quantitative studies (34$50 \%)[16,17]$ and qualitative studies [27-29] conducted in Northern Norway. These studies are, however, not directly comparable to our study, due to smaller number of participants, different populations and study methods. Our study is a large, unselected cohort study not limited to people with health concerns or experience with TM. In addition, as use of TM is not commonly spoken of $[30,31]$ use of TM might have been concealed when filling in the questionnaire. Also the fact that the TM provider often is contacted by people in the patients network [27] and not by the patients themselves, might have led to an under-report of such use due to recall 
Table 2 Health related issues in the total sample and among users and non-users of TM

\begin{tabular}{|c|c|c|c|c|c|c|c|}
\hline & \multicolumn{2}{|c|}{$\begin{array}{l}\text { Prevalence in the total } \\
\text { sample }\end{array}$} & \multicolumn{2}{|c|}{$\begin{array}{l}\text { Proportion using } \\
\text { TM }\end{array}$} & \multicolumn{2}{|c|}{$\begin{array}{l}\text { Proportion not using } \\
\text { TM }\end{array}$} & \multirow[t]{2}{*}{$p$-value* } \\
\hline & $\%$ & $n^{* *}$ & $\%$ & $n$ & $\%$ & $n$ & \\
\hline Current state of health & & & & & & & $<0.001$ \\
\hline Poor & 32.0 & 4983 & 17.5 & 874 & 82.5 & 4109 & \\
\hline Good & 68.0 & 10,565 & 11.7 & 1233 & 88.3 & 9332 & \\
\hline \multicolumn{8}{|l|}{ Physiological problems } \\
\hline Daily cough & 16.0 & 2134 & 15.0 & 320 & 85.0 & 1814 & 0.059 \\
\hline Heart attack & 4.1 & 614 & 13.5 & 83 & 86.5 & 531 & 0.925 \\
\hline Angina pectoris & 6.7 & 1006 & 17.4 & 175 & 82.6 & 831 & $<0.001$ \\
\hline Cerebral stroke/brain haemorrhage & 2.5 & 369 & 14.6 & 54 & 85.4 & 315 & 0.534 \\
\hline Multiple sclerosis & 0.3 & 38 & 26.3 & 10 & 73.7 & 28 & 0.021 \\
\hline Fracture & 11.5 & 1764 & 12.4 & 219 & 87.6 & 1545 & 0.104 \\
\hline Asthma & 10.7 & 1625 & 18.1 & 294 & 81.9 & 1331 & $<0.001$ \\
\hline Chronic bronchitis & 4.6 & 694 & 16.4 & 114 & 83.6 & 580 & 0.052 \\
\hline Diabetes & 4.3 & 654 & 14.1 & 92 & 85.9 & 562 & 0.037 \\
\hline Fibromyalgia/chronic pain syndrome & 9.7 & 1432 & 20.5 & 294 & 79.5 & 1138 & $<0.001$ \\
\hline Ulcerous colitis & 1.2 & 175 & 22.3 & 39 & 77.7 & 136 & 0.001 \\
\hline Pain/stiffness in muscles or joints for at least three months last year & 42.7 & 6392 & 15.7 & 1006 & 84.3 & 5386 & $<0.001$ \\
\hline Psychological problems & 11.7 & 1741 & 20.7 & 361 & 79.3 & 1380 & $<0.001$ \\
\hline Sad/depressed & 12.9 & 1699 & 20.3 & 349 & 79.7 & 1368 & $<0.001$ \\
\hline Insomnia & 35.3 & 4612 & 15.9 & 733 & 84.1 & 3879 & $<0.001$ \\
\hline Unable to cope with difficulties last 14 days & & & & & & & $<0.001$ \\
\hline No & 78.2 & 10,298 & 12.3 & 1262 & 87.7 & 9036 & \\
\hline Sometimes & 19.1 & 2516 & 18.5 & 466 & 81.5 & 2050 & \\
\hline Often & 1.9 & 249 & 23.7 & 59 & 76.3 & 190 & \\
\hline Almost all the time & 0.8 & 108 & 26.9 & 29 & 73.1 & 79 & \\
\hline Do you sometimes feel lonely? & & & & & & & $<0.001$ \\
\hline No & 61.1 & 8104 & 12.3 & 995 & 87.7 & 7109 & \\
\hline Sometimes & 35.3 & 4679 & 15.5 & 726 & 84.5 & 3953 & \\
\hline Often & 3.6 & 480 & 21.7 & 104 & 78.3 & 376 & \\
\hline
\end{tabular}

* Pearson's chi-square test ** Due to different number of respondents to the three questionnaires used in the study $(\mathrm{Q} 1=16,544, \mathrm{Q}=15,730$ and Q3 $=13,547)$ and missing responses to some of the questions, the number of respondents in single questions does not always add up to $n=16,544$

bias. The patients might have forgotten that a TM provider has been contacted on their behalf, in particular in cases where the TM care was conducted as distant healing.

Our finding of $25.7 \%$ use of a TM provider among the Sami participants is somewhat lower than previous findings among Sami patients and Alaska Natives where $46-68 \%$ reported to have seen a traditional healer [17, 32]. The lower use found in our study may be due to the fact that the participants were recruited outside a health care setting among mostly healthy individuals, while the compared studies included a more selective study group.

The finding of TM use in $9.1 \%$ of the Non-Sami participants is somewhat lower than Sørlie et al. found where
$37.8 \%$ of the Norwegian patients treated in a psychiatric hospital reported use of TM [17]. This is expected due to the fact that the participants in Sørlie's study not only had a health concern, but also a psychiatric health concern that both in previous studies $[28,29]$ and in our study is found to be a strong predictor for TM use. The finding of $9 \%$ use of a TM provider in the Non-Sami participants is, however, in line with the use of a complementary and alternative medicine (CAM) provider in general found in two large cohort studies in mid- and Northern Norway in the same period [33, 34]. This is despite the fact that these studies included all kinds of CAM providers and not only the use of TM providers. The reason for this might be that those studies reported CAM use within the last year only, while the present study reported ever use of TM. 
The highest use of TM was found among participants suffering from multiple sclerosis (MS), ulcerous colitis and psychological problems. These are all health challenges with limited treatment options within public health care, leading to a search for additional health approaches. For psychological problems, Kiil et al. found that Sami patients found the explanation and treatment of psychological disorders among TM providers more trustworthy and less stigmatizing than the treatment offered within the public health care, and more in line with their own cultural explanation model for such disease $[28,29]$.

\section{Associations for TM use}

The strong association between TM use and cultural affiliation as a Sami is in accordance with findings of TM use in Native Americans [35]. As TM is considered tacit knowledge, rarely revealed to people perceived as outsiders [31, 36], the tradition might have been better kept within the Sami communities than in the Non-Sami $[30,31]$. The reason for keeping the healing tradition hidden may partly be due to the witch process following the imposition of the Christianity in Norway. This led to a more hidden practice of TM as traditional healers were accused of witchery. Since the Sami people had a language not understandable for Norwegians and lived in communities often separated from Norwegian communities, the TM knowledge might have been better kept among the Sami than the Norwegian population.

One of these communities is the Laestadian church, established by the Sami priest Lars Levi Laestadius. In this church community, the sermons were conducted in Sami and the Sami culture was valued, making a safe space to continue their healing traditions. Today, the most frequently used TM in this church community is religious healing, conducted by gifted people who read bible verses over the persons illness [30]. This is in line with religious traditions across the world displaying beliefs in healing through prayer [37].

The rather high number of Non-Sami using TM in areas with Norwegian and Sami population might be due to participation in churches community where TM is actively used, and a respect for the traditional healers and their knowledge. The lack of medical doctors in the studied areas up to recent times, might have led to continued use of TM [38]. As the TM normally is offered for free or exchanged with small gifts [36], their service has been available also for people with limited financially resources. This might be one of the reasons why TM is still widely used, in particular among the participants with low income. In addition, some of the participants categorized as Non-Sami in our study, may have Sami origin. The harsh official policy to assimilate the Sami into the Norwegian culture and abandoning their Sami language was effective. Today, many people of Sami origin regard themselves as Norwegians, however, Sami culture and practices might still be present.

The high use of TM in region 1, the inland of Finnmark County, might be due to the almost exclusive Sami population and the strong tradition of reindeer herding in this area. Reindeer herding is a lifestyle including the whole family. The families have traditionally lived a nomadic life, following their reindeers. On the tundra, the absence of medical doctors was total and people needed to rely on their own knowledge when illness and injuries occurred. As the ability to heal is often inherited from older family members to younger, the families ensure that the knowledge is available when needed. The lower use of TM found in this study compared to what was found by Efskind et al. 30 years earlier [16], suggest a decrease in the TM use, despite the factors mentioned. TM practitioners express worries for the future as many now finds it more difficult than before to find family members to take over the role as a TM provider [39].

The finding of no differences between TM users and non-users of TM concerning years of education is in line with findings in recent studies for the use of CAM in general [40]. For TM in particular, this finding might suggest that the use of TM is strongly connected to the person's tradition and identity, and not influenced by external circumstances such as formal education.

\section{Strengths and limitations}

The main strength of this study is the large sample size $(n=16,544)$, the high response rate $(60 \%)$, and the unselected sample where all residents aged 30 and aged $36-78 / 79$ years in the selected regions were invited. As large parts of the traditional Sami settlement regions were included, the findings of use of TM among Sami people could be regarded representative of the Sami population living in Norway. However, the number of TM users with non-Sami background does not necessarily reflect the TM use among this group in general, since only rural parts of northern and mid-Norway were included. The selected municipalities cover only about $1 \%$ of the total population of Norway.

The cross-sectional design of the study makes it difficult to suggest causal relationships between TM use and other factors studied. We can therefore not draw the conclusion that the TM reported was used for the health complaints described by the TM users. The TM might have been used before the complaint appeared, as the use of TM is continuous and not limited to a certain time frame. Further, as traditional healer was not defined apart from the examples of such given in the parenthesis, the participants might have varied in their understanding of how to understand the term traditional 
healer. Another limitation of this study is that it was conducted in 2003-2004 and therefore not necessarily reflects the TM use today. This is, however, so far the only population based study in Norway collecting data on the use of TM and will therefore be important for future studies due to the possibility to investigate trends in TM use in Northern Norway.

\section{Conclusions}

Our study suggests that TM is widely used in Northern Norway and that people with a Sami background use more TM than Non-Sami living in the same areas. Further studies are necessary to examine the development of TM use in Norway and the use of TM should be studied also in areas with mainly Norwegian inhabitants. There is also a lack of studies describing prevalence and associations for TM use among the Sami in Sweden, Finland and Russia.

\section{Abbreviations}

CAM: Complementary and Alternative Medicine; SAMINOR: Health and Living Conditions in Regions with Sami and Norwegian Populations; TM: Traditional medicine

\section{Acknowledgements}

We thank the participants and the SAMINOR Study for providing data to this study. We also thank UiT The Arctic University of Norway and The Norwegian Ministry of Health and Care Services who funded this research. The publication charges for this article have been funded by a grant from the publication fund of UiT The Arctic University of Norway.

\section{Funding}

The SAMINOR 1 Survey was funded by The Norwegian Ministry of Health and Care Services.

\section{Availability of data and materials}

The raw dataset is not available due to Norwegian privacy regulations. Applicants for any data must be prepared to conform to Norwegian privacy regulations.

\section{Authors' contributions}

$A E K$ and $A R B$ conceived the research questions and analyse strategies of this paper, AEK and MM performed the initial and final analyses. AEK, TS, ARB and MM drafted the initial version of the paper and all authors reviewed subsequent versions, read, and approved the final manuscript.

\section{Ethics approval and consent to participate}

Participant security and protection was the responsibility of the central administration of the SAMINOR Study. The study was approved by the Norwegian Data Inspectorate and recommendation by the local ethics committee (P REK V 22/2002). Written consent was obtained from all the participants

\section{Consent for publication}

Not applicable.

\section{Competing interests}

The authors declare that they have no competing interests.

\section{Publisher's Note}

Springer Nature remains neutral with regard to jurisdictional claims in published maps and institutional affiliations.

\section{Author details}

${ }^{1}$ National Research Center in Complementary and Alternative Medicine (NAFKAM), Department of Community Medicine, Faculty of Health Science,
UiT The Arctic University of Norway, Tromsø, Norway. ${ }^{2}$ Centre for Sami Health Research, Department of Community Medicine, Faculty of Health Science, UiT The Arctic University of Norway, Tromsø, Norway. ${ }^{3}$ Department of Medicine, University Hospital of North Norway, Harstad, Norway.

Received: 29 June 2017 Accepted: 28 November 2017

Published online: 12 December 2017

\section{References}

1. Om samepolitikken [About the Sami politics]. In: Edited by Ministry DkkorTRMaR, vol. 55. regeringen.no: Det kongelige kommunal- og regionaldepartement. The [Royal Municipal and Regional Ministry]; 2000.

2. Lund E, Melhus M, Hansen KL, Nystad T, Broderstad AR, Selmer R, LundLarsen PG. Population based study of health and living conditions in areas with both Sami and Norwegian populations-the SAMINOR study. Int J Circumpolar Health. 2007;66(2):113-28.

3. Sami people. https://en.wikipedia.org/wiki/Sami_people. Accessed 31 Aug 2017.

4. Skogvang SF. Samerett [Sami rights]. Oslo: Universitetsforlaget; 2009

5. Josefsen E, Mörkenstam U, Saglie J. Different institutions within similar states: the Norwegian and Swedish Sámediggis. Ethnopolitics. 2015;14(1):32-51.

6. Urbefolkningen i tall - samisk statistikk. [Sami Statistics Indigenous people in numbers - Sami statistics]. 2012. https://www.ssb.no/befolkning/artikler-ogpublikasjoner/urbefolkningen-i-tall-samisk-statistikk. Accessed 29 Aug 2017.

7. Lovdata. Act No. 64 of 27 June 2003 relating to the alternative treatment of disease, illness, etc. 2003. http://www.ub.uio.no/ujur/ulovdata/lov-20030627064-eng.pdf. Accessed 27 June 2015.

8. NAFKAM-undersøkelsen 2016, Bruk av alternativ behandling i Norge [The NAFKAM survey 2016. Use of complementary and alternative medisin in Norway]. 2016. http://www.nifab.no/hva_er_alternativ_behandling/tall_og_ fakta. Accessed 13 Sept 2017

9. Traditional Medicine: Definitions. http://who.int/medicines/areas/traditional/ definitions/en/. Accessed 7 June 2017.

10. General Guidelines for Methodologies on Research and Evaluation of Traditional Medicine. 2000. http://apps.who.int/iris/bitstream/10665/66783/1/ WHO_EDM_TRM_2000.1.pdf. Accessed 23 May 2017.

11. Samisk folkemedisin [Sami folk medicine]. 2013. http://nifab.no/ behandlingsformer/samisk_folkemedisin/bakgrunn. Accessed 30 Nov 2016

12. Larsen A, Salamonsen A, Kristoffersen AE, Stub T: "The prayer circles in the air": a qualitative study about traditional healers from Northern Norway. Int J Circumpolar Health. In press.

13. Sexton R, Stabbursvik EA. Healing in the Sami North. Cult Med Psychiatry. 2010;34(4):571-89.

14. Miller BH. Connecting and correcting: a case study of Sami healers in Porsanger. Leiden: CNWS publications, Research School CNWS; 2007.

15. Kiil MA, Salamonsen A. Embodied health practices:the use of traditional healing and conventional medicine in a North Norwegian community. Acad J Interdiscip Stud. 2013:2(3):483-8.

16. Efskind $L$, Johansen AT. Folkemedisin og overnaturlig helbredelse [Folk medicine and supernatural healing]. Tidsskr norske Leageforen. 1976;96:1582.

17. Sorlie T, Nergard JI. Treatment satisfaction and recovery in Saami and Norwegian patients following psychiatric hospital treatment: a comparative study. Transcult Psychiatry. 2005;42(2):295-316.

18. Bakken K, Melhus M, Lund E. Use of hypnotics in Sami and non-Sami populations in northern Norway. Int J Circumpolar Health. 2006;65(3): 261-70

19. Båk'te VA: Den samiske befolkning i Nord-Norge [The Lappish population in Northern Norway], vol. 107. Oslo: Statistics Norway; 1978.

20. Naseribafrouei A, Eliassen BM, Melhus M, Broderstad AR. Ethnic difference in the prevalence of pre-diabetes and diabetes mellitus in regions with Sami and non-Sami populations in Norway - the SAMINOR1 study. Int J Circumpolar Health. 2016;75(1):31697.

21. Nergård Jl. Det skjulte Nord-Norge [the hidden Northern Norway]. Oslo: Ad Notam Gyldendal; 1994.

22. Church of Norway. 2017. https://en.wikipedia.org/wiki/Church_of_Norway. Accessed 28 Aug 2017.

23. Church of Norway. http://www.ssb.no/en/kultur-og-fritid/statistikker/kirke_ kostra/aar. Accessed 28 Aug 2017.

24. Laestadianism. 2017. https://en.wikipedia.org/wiki/Laestadianism. Accessed 28 Aug 2017. 
25. Minde H. Constructing 'Laestadianism': a case for Sami survival? 1. Acta Borealia. 1998;15(1):5-25.

26. Molland E, Bloch-Hoell NE. Læstadianere [Laestadians]. In: Store norske leksikon; 2016.

27. Larsen A, Salamonsen A, Kristoffersen AE, Stub T. "We own the illness": a qualitative study about traditional network in two Sami communities in Northern Norway. Int J Circumpolar Health. In press.

28. Kiil MA. The paradox of home: understanding northern Troms as a therapeutic landscape. In: Miller BH, editor. Idioms of Sami Health and Healing Patterns of Northern Traditional Healing, vol. 2. Alberta: University of Alberta Press; 2015. p. 131-56.

29. Kiil MA. A room with a view: navigating continuity and rupture within the traditional healing repertoire of Northern Troms. In: Naskali P, Seppänen M Begum S, editors. Arctic change and elderly exclusion: an interdisciplinary analysis. London: Routledge; 2016. p. 231-47.

30. Larsen AlL. Fortellinger om læsing [Stories about "reading" (traditional healing)]. Master Thesis. Tromsø: Uit The Arctic University of Norway; 2012.

31. Hætta AK. Secret knowledge: the management and transformation of traditional healing knowledge in the Marka Sámi villages. Master Thesis. Tromsø: UiT The Arctic University of Norway; 2010.

32. Van Sickle D, Morgan F, Wright AL: Qualitative study of the use of traditional healing by asthmatic Navajo families. Am Indian Alsk Native Ment Health Res 2003, 11(1):1-18.

33. Kristoffersen AE, Norheim AJ, Fonnebo VM. Any difference? Use of a CAM provider among cancer patients, coronary heart disease (CHD) patients and individuals with no cancer/CHD. BMC Complement Altern Med. 2012;12:1

34. Steinsbekk A, Rise MB, Johnsen R. Changes among male and female visitors to practitioners of complementary and alternative medicine in a large adult Norwegian population from 1997 to 2008 (The HUNT studies). BMC Complement Altern Med. 2011;11:61.

35. Buchwald D, Beals J, Manson SM. Use of traditional health practices among Native Americans in a primary care setting. Med Care. 2000;38(12):1191-9.

36. Myrvoll M: "Bare gudsordet duger": om kontinuitet og brudd i samisk virkelighetsforståelse ["Only Gods word works": continuity and rupture in Sami worldview]. PhD. 2011.

37. Andrade C, Radhakrishnan R. Prayer and healing: a medical and scientific perspective on randomized controlled trials. Indian J Psychiatry. 2009;51(4):247-53.

38. Aarbakkeutvalget. NOU 1998:21 Alternativ medisin [NOU 1998:21 Alternative Medicine]. vol. 21. In: Omsorgsdepartementet Ho, editor. Oslo: Helse og omsorgsdepartementet; 1998.

39. Myrvoll M. Kunnskapstradisjon og samiske helbredere [Tradition knowledge and Sami healers]. In: Altern I, Minde G, editors. Samisk folkemedisin i dagens Norge : rapport fra seminar i regi av Institutt for sosiologi og Senter for samiske studier, Tromsø 26-27 nov 1998. Tromsø: Senter for samiske studier; 2000. p. 35-46.

40. Kristoffersen AE, Stub T, Salamonsen A, Musial F, Hamberg K. Gender differences in prevalence and associations for use of CAM in a large population study. BMC Complement Altern Med. 2014;14:463.

\section{Submit your next manuscript to BioMed Central and we will help you at every step:}

- We accept pre-submission inquiries

- Our selector tool helps you to find the most relevant journal

- We provide round the clock customer support

- Convenient online submission

- Thorough peer review

- Inclusion in PubMed and all major indexing services

- Maximum visibility for your research

Submit your manuscript at www.biomedcentral.com/submit 